\title{
Growth of GalnTIAs layers on InP by molecular beam epitaxy
}

\author{
F. Sánchez-Almazán, M. Gendry, P. Regreny, E. Bergignat, G. Grenet, \\ and G. Hollinger ${ }^{\text {a) }}$ \\ Ecole Centrale de Lyon, LEOM, (UMR CNRS 5512), 69131 Ecully Cedex, France \\ J. Olivares and G. Bremond \\ INSA de Lyon, LPM, (UMR CNRS 5511), 69621 Villeurbanne Cedex, France \\ O. Marty and M. Pitaval \\ Université Lyon 1, LENAC, 69621 Villeurbanne Cedex, France \\ B. Canut \\ Université Lyon 1, DPM, (UMR CNRS 5586), 69621 Villeurbanne Cedex, France
}

(Received 11 August 2000; accepted 5 February 2001)

Growth of GaInTlAs alloys on $\operatorname{InP}(001)$ has been attempted by solid source molecular beam epitaxy. Thallium incorporation into $\mathrm{Ga}_{1-x} \mathrm{In}_{x}$ As matrices was studied as a function of substrate temperature, arsenic overpressure, matrix composition, and growth rate. At high temperatures $\left(>350^{\circ} \mathrm{C}\right)$ thallium evaporates, whereas at intermediary temperatures $\left(270-350{ }^{\circ} \mathrm{C}\right)$ thallium segregates into droplets on the surface. Only in the low temperature range $\left(180-260^{\circ} \mathrm{C}\right)$ can thallium be incorporated in some conditions, leading to mirror-like surfaces. Up to $18 \% \mathrm{Tl}$ content was incorporated into a $\mathrm{Ga}_{0.70} \mathrm{In}_{0.30}$ As matrix and up to $40 \% \mathrm{Tl}$ into a GaAs matrix. For these high $\mathrm{Tl}$ concentrations, $\mathrm{Tl}$ droplets are avoided and $\mathrm{Tl}$ incorporation is achieved only when using high arsenic pressures. However, this limits surface adatom diffusion and leads to amorphous, polycrystalline, or twinned materials. Finally, a narrow window for single-crystal growth has been found for low $\mathrm{Tl}$ contents (4\%) using optimized growth conditions with low V/III pressure ratios and high growth rates. (C) 2001 American Vacuum Society. [DOI: 10.1116/1.1359530]

\section{INTRODUCTION}

As and $\mathrm{P}$ based ternary or quaternary thallium alloys have been recently proposed as new infrared materials for long wavelength operation. According to theoretical predictions, TIP and TlAs have a negative band gap and a marginally stable zinc-blende structure with lattice parameters close to those of InP and InAs, respectively. ${ }^{1}$ Consequently, low band gap GaInTIP and GaInTlAs alloys can theoretically be prepared lattice matched to InP or GaAs. As an example, it is expected to reach operation wavelengths of about $2.7 \mu \mathrm{m}$ with $26 \% \mathrm{Tl}$ in $\mathrm{Ga}_{0.54} \mathrm{In}_{0.20} \mathrm{Tl}_{0.26}$ As layers, lattice matched to InP.

These predictions have stimulated several experimental studies. Growth of P and As based Tl alloys has been tried on GaAs, InP, and InAs substrates using solid source molecular beam epitaxy (SSMBE), gas source MBE (GSMBE) and metalorganic chemical vapor deposition (MOCVD). ${ }^{2-13}$ Thallium is more volatile than Ga and In with a vapor pressure of $10^{-7}$ and $10^{-6}$ Torr around 320 and $360^{\circ} \mathrm{C}$, respectively, whereas the corresponding temperatures for indium are around 540 and $600^{\circ} \mathrm{C}$. Consequently, the standard growth temperature for GaInTlAs alloys should be around $350{ }^{\circ} \mathrm{C}$ (i.e., the highest temperatures for which the thallium sticking coefficient should be equal or near equal to 1 ), to compare with $500-550{ }^{\circ} \mathrm{C}$ for GaInAs alloys. When using standard growth temperatures, most authors found that thallium accumulates on the surface in the form of metallic drop-

${ }^{a}$ Electronic mail: Guy.Hollinger@ec-lyon.fr lets. This encouraged studies either at higher temperatures $\left(400-450{ }^{\circ} \mathrm{C}\right)$ or at lower temperatures $\left(<250^{\circ} \mathrm{C}\right)$.

For growths performed at high temperatures, contradictory conclusions have been reached and the situation is presently rather confusing. Using GSMBE, Asahi and co-workers ${ }^{2-5}$ claimed successful growth of TIP, InTIP, GaTIP, GaInTIP, and GaInTlAs alloys in the growth temperature range of $400-450^{\circ} \mathrm{C}$. In these works, experimental evidence for $\mathrm{Tl}$ incorporation is only based on $\mathrm{x}$-ray and electro-optical (photoluminescence and photoconductance) results which are only indirect characterizations. Hübener et $a{ }^{6}{ }^{6}$ claimed the successful fabrication by SSMBE of a GaTlP light emitting diode (LED) grown on GaAs and emitting at $1.3 \mu \mathrm{m}$. Razeghi et $\mathrm{ll}^{7}$ also claimed the growth by low pressure MOCVD of $(\mathrm{InP})_{1-x}\left(\mathrm{TlP}_{3}\right)_{x}$ with $\mathrm{Tl}$ content of $x=0.6$, an evaluation exclusively based on photoconductance measurements. However, none of these authors gave clear evidence of $\mathrm{Tl}$ incorporation since they did not measure the thallium concentration using analytical techniques. By contrast, Antonell et al., ${ }^{8}$ Wei et al. ${ }^{9}$ and Sánchez et al., ${ }^{12,13}$ who measured $\mathrm{Tl}$ concentrations using analytical techniques, did not succeed in incorporating $\mathrm{Tl}$ into $\mathrm{InP}, \mathrm{GaInAs}$, and InAs matrices using $\mathrm{GSMBE}^{8}$ or SSMBE. ${ }^{9,12,13}$ They reported that, for substrate temperatures higher than 350$400{ }^{\circ} \mathrm{C}$, thallium atoms evaporate and consequently are not incorporated.

Results for growth performed at low temperature are less contradictory. Antonell et al. ${ }^{8}$ described the formation of an "InTlAs" phase at low temperature $\left(275^{\circ} \mathrm{C}\right)$ together with metallic droplets. Lubyshev et al. ${ }^{10}$ reported MBE growth at 
$200{ }^{\circ} \mathrm{C}$ of $\mathrm{Tl}_{x} \mathrm{Ga}_{1-x}$ As on $\mathrm{GaAs}$ with an estimated maximum $\mathrm{Tl}$ content of $5 \%$ but with metallic droplets on the surface. Sánchez et al. ${ }^{12,13}$ achieved the incorporation of up to $18 \%$ $\mathrm{Tl}$ in mirror-like InGaTlAs layers grown at $230^{\circ} \mathrm{C}$ but these layers were not single crystalline.

The aim of this work is to clarify the incorporation behavior of $\mathrm{Tl}$ in $\mathrm{III}-\mathrm{V}$ matrices in a wide range of substrate temperatures $\left(150-500^{\circ} \mathrm{C}\right)$ and to try to grow GaInTlAs alloys on InP by SSMBE. Our approach was, first to construct a phase diagram for the GaInAs:Tl system in order to define growth conditions for $\mathrm{Tl}$ incorporation, $\mathrm{Tl}$ surface segregation, and $\mathrm{Tl}$ evaporation, as a function of growth temperature and $\mathrm{Tl}$ flux. Then we looked (unsuccessfully) for incorporation in the high temperature regime and finally we found conditions, in the low temperature regime, for $\mathrm{Tl}$ incorporation and single-crystalline growth.

\section{EXPERIMENT}

The epitaxial layers were grown on epiready semiinsulating $\mathrm{InP}$ (001) substrates using a Riber 2300 reactor equipped with high capacity $\mathrm{P}$ and As cracking cells. High growth temperatures were measured with an optical pyrometer which was calibrated taking, as reference, the melting point of InSb at $525^{\circ} \mathrm{C}$. Low temperatures were estimated using a combination of thermocouple temperatures, values of the power delivered to the heater filament, and indium melt measurements. Before growth, InP substrates were deoxidized under a $P_{2}$ flux with a beam equivalent pressure (BEP) of $10^{-5}$ Torr at $530^{\circ} \mathrm{C}$. For all grown structures, an $0.2 \mu \mathrm{m}$ thick InP buffer layer was grown at $480{ }^{\circ} \mathrm{C}$ using a $\mathrm{P}_{2}$ cracking temperature of $800^{\circ} \mathrm{C}$, the optimum temperature to obtain the minimal incorporation of nonintentional impurities. We have explored a wide range of growth conditions for GaInAs:Tl materials by varying four main parameters: the growth temperature ranging from 450 to $150{ }^{\circ} \mathrm{C}$, the $\mathrm{Tl}$ flux, the arsenic pressure, the composition of the $\mathrm{Ga}_{1-x} \mathrm{In}_{x}$ As host matrix, and in some cases the growth rate. The surface morphology of the layers was observed using Nomarski optical microscopy and scanning electronic microscopy (SEM). The incorporation of thallium was systematically investigated using secondary ion mass spectrometry (SIMS) profile measurements. Rutherford backscattering spectrometry (RBS) was utilized to determine the absolute $\mathrm{Tl}$ concentration and also to calibrate SIMS data. X-ray photoelectron spectroscopy (XPS) measurements were performed to evaluate $\mathrm{Tl}$ concentrations on the surface and into the bulk. Energy dispersive $\mathrm{x}$-ray analysis (EDX) performed in SEM equipment was applied to characterize layers with droplets on the surface. The surface structural properties of the layers were studied during growth using reflection high energy electron diffraction (RHEED) and after growth using Nomarski microscopy and atomic force microscopy (AFM). Double crystal x-ray diffraction (DCXRD) and transmission electron microscopy (TEM) were employed to investigate the bulk structural properties.
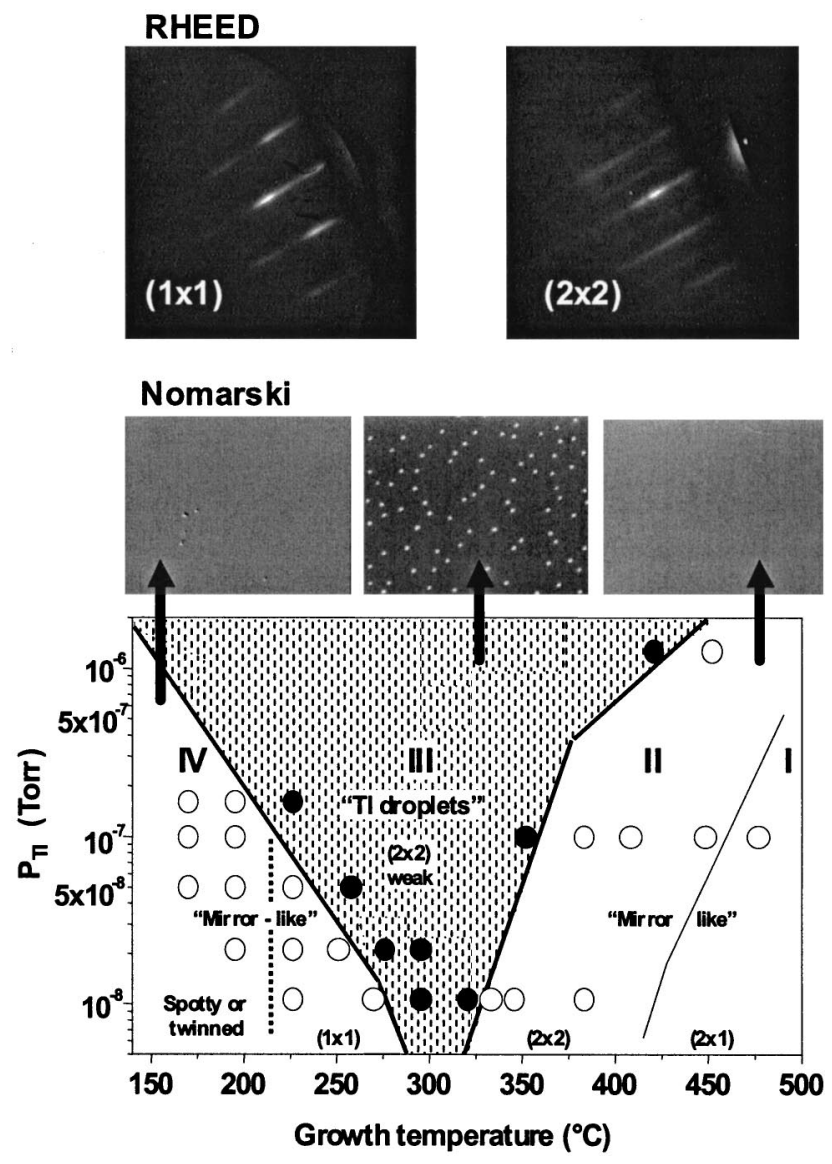

FIG. 1. Phase diagram for GaInAs:Tl showing four growth regimes for thallium incorporation when $\mathrm{Tl}$ pressure and growth temperature are varied. Regions I and II are associated with $\mathrm{Tl}$ evaporation and $\mathrm{Tl}$ surface segregation, respectively. Region III is associated with Tl surface segregation and formation of metallic $\mathrm{Tl}$ surface droplets. Tl incorporation occurs for region IV. Surfaces in region II are covered by $\sim 0.1-0.2 \mathrm{ML}$ of $\mathrm{Tl}$ atoms which leads to a $(2 \times 2)$ surface reconstruction. The phase diagram was constructed mainly for $\mathrm{Ga}_{1-x} \mathrm{In}_{x}$ As tensively strained matrices grown at $1 \mu \mathrm{m} / \mathrm{h}$. The V/III ratio was in the 5-11 range. Also shown are the corresponding Nomarski photographs of surface morphologies and RHEED patterns taken in the [110] azimuth.

\section{PHASE DIAGRAM FOR THE GalnAs-TI SYSTEM}

Our preliminary objective was to construct a "phase diagram" for the GaInAs:Tl system in order to look for a $\mathrm{Tl}$ incorporation window between the "droplet" regime and the "mirror- like" regime, when varying the thallium flux and the growth temperature but keeping $\mathrm{Ga}$, In, and As fluxes constant. A careful study of the RHEED patterns during growth and an examination of the surface morphology of the corresponding samples have allowed us to define four regions as shown in Fig. 1.

When decreasing the substrate temperature, the following regions have been found in sequence:

(1) Region I: mirror-like surfaces and RHEED patterns with $(2 \times 1)$ bulk streaks (similar to $\mathrm{Ga}_{1-x} \mathrm{In}_{x}$ As patterns),

(2) Region II: mirror like surfaces and $(2 \times 2)$ surface reconstruction,

(3) Region III: surface droplets and weak RHEED diagrams, and 
(4) Region IV: mirror-like surfaces and no single-crystal RHEED pattern.

Region I corresponds to Tl-free GaInAs because the $\mathrm{Tl}$ sticking coefficient is almost equal to 0 . Region II is characterized by a $(2 \times 2)$ surface reconstruction induced by surface $\mathrm{Tl}$ atoms. Such a reconstruction has been already reported by others $^{3,4,10}$ for $\mathrm{Tl}$ exposed InP, GaAs, InAs, and GaInAs. Using XPS, we found that the $(2 \times 2)$ surface reconstruction in region II is associated to the presence of about $0.1-0.2$ thallium monolayer on the surface. In regions III and IV, it is believed that the Tl sticking coefficient $\Theta_{\mathrm{Tl}}$ is equal or close to 1 since the onset for significant $\mathrm{Tl}$ desorption is around $320-360^{\circ} \mathrm{C}$. When traveling in Fig. 1 from right to left through regions I, II, and III, the whole process can be roughly understood as an effect of the $\mathrm{Tl}$ sticking coefficient increasing from 0 to 1 when the growth temperature is decreasing. When the number of $\mathrm{Tl}$ atoms increases on surface, $\mathrm{Tl}$ atoms first form a surface overstructure and then when the coverage becomes sufficient for metallic $\mathrm{Tl}-\mathrm{Tl}$ interaction to emanate, metallic droplets appear. The abrupt phase boundary between regions III and IV is more astonishing and will thus be in the following the subject of a special study . However, it may be thought as the result of the surface atom mobility decreasing as temperature decreases, while the sticking coefficient being equal to 1 .

\section{A. Growth at high temperatures (regions I, II, and III)}

First we grew a set of GaInAs: Tl layers covering a wide variety of conditions in the "high temperature" (350$480^{\circ} \mathrm{C}$ ) regions I, II, and III. Tl pressures (BEP) were varied from $10^{-8}$ to $10^{-6}$ Torr. The arsenic pressure was 4 $\times 10^{-6}$ Torr and the temperature of the As cracker cell was fixed at $800^{\circ} \mathrm{C}$. After growing a $0.2 \mu \mathrm{m}$ thick InP buffer layer and then a $0.4 \mu \mathrm{m} \mathrm{Ga} a_{0.47} \mathrm{In}_{0.53}$ As buffer layer at $480{ }^{\circ} \mathrm{C}$, $0.4 \mu \mathrm{m}\langle$ GaInTlAs》 layers were grown at various temperatures from 350 to $480^{\circ} \mathrm{C}$. The growth rate of the layers was $1.2 \mu \mathrm{m} / \mathrm{h}$. Some of these growth conditions were very similar to those used by Asahi and co-workers. ${ }^{4,5}$ Four compositions for the host tensilely strained matrices have been tried: GaAs, $\mathrm{Ga}_{0.70} \mathrm{In}_{0.30} \mathrm{As}, \mathrm{Ga}_{0.58} \mathrm{In}_{0.42} \mathrm{As}$, and $\mathrm{Ga}_{0.52} \mathrm{In}_{0.48} \mathrm{As}$ which correspond to $3.6 \%, 1.6 \%, 0.77 \%$, and $0.36 \%$ lattice mismatch to InP, respectively. Special attention was paid to find an incorporation window just at the boundary between

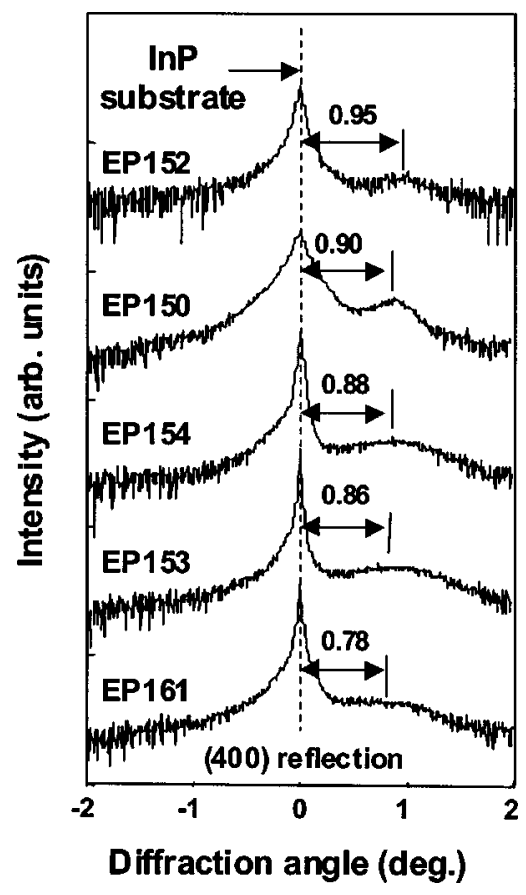

FIG. 2. Double crystal x-ray diffraction curves for different $\mathrm{Ga}_{0.70} \mathrm{In}_{0.30} \mathrm{As}: \mathrm{Tl}$ samples compared to that of a reference $\mathrm{Tl}$ free sample. Shifts are attributed to variations in the relaxation degree of the layers and not to $\mathrm{Tl}$ incorporation.

the droplet regime (region III) and the evaporation regime (region II). The idea was to use the tensile matrix effect to stabilize $\mathrm{Tl}-\mathrm{As}$ bonds and thus to favor $\mathrm{Tl}$ incorporation in regions where the sticking coefficient is normally equal to zero on lattice-matched materials. No significant $\mathrm{Tl}$ incorporation was found by SIMS in all the samples which show either $\mathrm{Tl}$ droplets, $\mathrm{Tl}$ surface segregation, or $\mathrm{Tl}$ evaporation. The highest $\mathrm{Tl}$ concentration levels detected by SIMS were always lower than $0.01 \%$. Some SIMS profiles showed, in some cases, an incorporation enhancement (by a factor of 2) from one sample to another but this was always far below a significant incorporation level. EDX measurements performed on the samples exhibiting droplets on surface revealed $\mathrm{Tl}$ only in the droplet areas and no $\mathrm{Tl}$ between the droplets. Figure 2 shows a set of DCXRD rocking curves of (400) reflection for some $\mathrm{Ga}_{0.70} \mathrm{In}_{0.30} \mathrm{As}$ : Tl layers (EP150, EP154, EP153, and EP161) compared to that of a Tl free $\mathrm{Ga}_{0.70} \mathrm{In}_{0.30} \mathrm{As}$ sample (EP152). The corresponding growth

TABLE I. Growth conditions for a set of $\mathrm{Ga}_{0.70} \mathrm{In}_{0.30} \mathrm{As}$ :Tl layers presenting the same $\mathrm{Ga}_{0.70} \mathrm{In}_{0.30} \mathrm{As}$ matrix composition and the same thickness $(2000 \AA)$. Only the thallium flux and the growth temperature are changed. Also given is the hypothetical $\mathrm{Tl}$ content, calculated assuming the same strain relaxation degree for all layers.

\begin{tabular}{lccccccc}
\hline \hline Sample & $\begin{array}{c}T_{c} \\
\left({ }^{\circ} \mathrm{C}\right)\end{array}$ & $\begin{array}{c}P_{\mathrm{Tl}} \\
(\text { Torr })\end{array}$ & $\begin{array}{c}P_{\mathrm{In}} \\
(\text { Torr })\end{array}$ & $\begin{array}{c}P_{\mathrm{Ga}} \\
(\text { Torr })\end{array}$ & $\begin{array}{c}\text { DCXRD } \\
\text { hypothetical } \\
\times \mathrm{Tl} \text { content }\end{array}$ & $\begin{array}{c}\text { Surface } \\
\text { morphology }\end{array}$ & $\begin{array}{c}\text { Droplets } \\
\text { per cm }{ }^{2}\end{array}$ \\
\hline EP152 (ref) & 450 & 0 & $1.5 \times 10^{-7}$ & $2.31 \times 10^{-7}$ & 0 & mirror like & 0 \\
EP150 & 450 & $10^{-7}$ & $1.5 \times 10^{-7}$ & $2.31 \times 10^{-7}$ & 0.06 & mirror like & 0 \\
EP154 & 425 & $10^{-7}$ & $1.5 \times 10^{-7}$ & $2.31 \times 10^{-7}$ & 0.04 & mirror like & 0 \\
EP153 & 450 & $10^{-6}$ & $1.5 \times 10^{-7}$ & $2.31 \times 10^{-7}$ & 0.03 & droplets & $9 \times 10^{2}$ \\
EP161 & 425 & $10^{-6}$ & $1.5 \times 10^{-7}$ & $2.31 \times 10^{-7}$ & 0.1 & droplets & $8 \times 10^{4}$ \\
\hline \hline
\end{tabular}


conditions are given in Table I. The epilayer-substrate peak separation, decreasing from EP152 (taken as reference) to EP161 could be interpreted as an indication of a possible Tl incorporation. For example, assuming a lattice parameter of $6.18 \AA$ for $\mathrm{TlAs}^{1}$ and assuming the same degree of strain relaxation $(20 \%)$ found in the reference layer (EP152), we would predict a thallium content ranging from $3 \%$ to $10 \%$. Since we know from SIMS and EDX measurements that there is no $\mathrm{Tl}$ incorporation, these shifts have to be actually related to a variation of the growth dependent degree of strain relaxation. Photoluminescence measurements at $4 \mathrm{~K}$ confirmed that there is no reduction in the band gap of the layers and thus no thallium incorporation achieved. Note that such $\mathrm{X}$-ray diffraction shifts have been interpreted by some authors as an indication of $\mathrm{Tl}$ incorporation. ${ }^{4}$ Our results show that isolated data from indirect characterization techniques are not reliable enough for claiming $\mathrm{Tl}$ incorporation. $^{14}$

\section{B. Growth at low temperatures (region IV)}

\section{Growth of defective GalnTIAs layers at low temperature}

As no incorporation was achieved at high temperatures and as droplets are formed at intermediary temperatures, only the low temperature domain appears suitable for the incorporation of thallium atoms during growth. The GaInAs:Tl system was further explored in the temperature range of $180-370{ }^{\circ} \mathrm{C}$. Besides this parameter, $\mathrm{Tl}$ incorporation in the $\mathrm{Ga}_{1-x} \mathrm{In}_{x}$ As matrix was also studied by varying the thallium pressures (BEP range of $10^{-8}-10^{-6}$ Torr), the arsenic pressures $\left(10^{-7}-2 \times 10^{-5}\right.$ Torr range, which corresponds to V/III BEP ratios varying from 1 to 50), and the indium compositions of the $\mathrm{Ga}_{1-x} \mathrm{In}_{x}$ As matrices $(x=0.3$, $0.42,0.48$, and 0.53 ). Growth rates were varied from 0.35 to $1.4 \mu \mathrm{m} / \mathrm{h}$. Before the GaInAs:Tl layers were grown in the temperature range of $180-370^{\circ} \mathrm{C}$, a $200 \AA$ thick GaInAs LM buffer layer was grown at $500{ }^{\circ} \mathrm{C}$, and cooled to the growth temperature GaInAs:Tl layer while maintaining a $(3 \times 4)$ RHEED reconstruction indicative of a good surface structural quality. The Tl, In, and Ga relative fluxes were chosen in order to achieve a GaInTlAs compound lattice matched to InP or slightly tensilely strained.

In some conditions, below $340^{\circ} \mathrm{C}, \mathrm{Tl}$ incorporation was achieved without any droplet formation leading to mirrorlike surfaces. A set of growth conditions leading to Tl incorporation and mirror-like surfaces is collected in Table II. At these low temperatures, the sticking coefficient of $\mathrm{Tl}$ atoms is 1 and a first-order composition of the mirror-like layers can be estimated from $\mathrm{Ga}$, In, and $\mathrm{Tl}$ fluxes, as given in Table II. The absolute concentration of thallium was more precisely evaluated using RBS (Fig. 3), EDX and XPS (Fig. 4) measurements confirming these estimations. SIMS profiles measured for several samples showed that the $\mathrm{Tl}$ concentration was homogeneous in depth and proportional to the incoming Tl flux (Fig. 5). As shown in Table II, the highest $\mathrm{Tl}$ concentration was found equal to $40 \%$ for a $\mathrm{GaAs}$ host matrix and a growth temperature of $180^{\circ} \mathrm{C}$ (EP414). It was
TABLE II. Growth conditions and atomic composition for several $\left(\mathrm{Ga}_{1-y} \mathrm{In}_{y}\right)_{1-x} \mathrm{Tl}_{x}$ As samples. The expected compositions were calculated from $\mathrm{Ga}$, In, and $\mathrm{Tl}$ beam pressures assuming an incorporation coefficient equal to 1 . The experimental compositions were evaluated by RBS.

\begin{tabular}{lcccrrrr}
\hline \hline & $\begin{array}{c}T_{c} \\
\text { Sample }\end{array}\left({ }^{\circ} \mathrm{C}\right)$ & $\begin{array}{c}P_{\mathrm{As}} \\
(\mathrm{Torr})\end{array}$ & $P_{\mathrm{Tl}} / P_{\mathrm{In}}$ & $\begin{array}{c}y \\
\% \mathrm{In}\end{array}$ & $\begin{array}{c}1-y \\
\% \mathrm{Ga}\end{array}$ & $\begin{array}{c}x \% \mathrm{Tl} \\
\text { expected }\end{array}$ & $\begin{array}{c}x \% \mathrm{Tl} \\
\mathrm{RBS}\end{array}$ \\
\hline EP306 & 230 & $1.5 \times 10^{-6}$ & 0.18 & 42 & 58 & 4.2 & 3.5 \\
$\mathrm{EP} 304$ & 180 & $1.5 \times 10^{-6}$ & 0.35 & 42 & 58 & 8.2 & 8 \\
$\mathrm{EP} 329$ & 180 & $1.5 \times 10^{-6}$ & 0.59 & 42 & 58 & 13 & 14 \\
$\mathrm{EP} 386$ & 200 & $10^{-5}$ & 0.60 & 30 & 70 & 15 & 18 \\
$\mathrm{EP} 398$ & 180 & $10^{-5}$ & 1.6 & 0 & 100 & 41 & 32 \\
$\mathrm{EP} 414$ & 180 & $10^{-5}$ & 2.25 & 0 & 100 & 49 & 40 \\
\hline \hline
\end{tabular}

also incorporated up to $18 \% \mathrm{Tl}$ into $\mathrm{Ga}_{0.70} \mathrm{In}_{0.30}$ As at $200{ }^{\circ} \mathrm{C}$ (EP386). $\mathrm{Tl}$ concentrations of $3.5 \%, 8 \%$, and $14 \%$ were also obtained in $\mathrm{Ga}_{0.58} \mathrm{In}_{0.42}$ As matrices for growths at 180, 180, and $230^{\circ} \mathrm{C}$, respectively (EP306, EP304, EP329).

At this point, it is important to note that $\mathrm{Tl}$ atoms are not systematically incorporated whatever the growth conditions are. A variation of some growth parameters, especially the growth temperature and the V/III ratio, can allow the shift towards an incorporation behavior (leading to mirror-like surfaces) or towards no incorporation behavior ( $\mathrm{Tl}$ atoms remaining segregated on the surface and giving droplets). As an example, when growth conditions are achieved at $200{ }^{\circ} \mathrm{C}$ in order to produce $\mathrm{Tl}$ incorporation [Fig. 6(a)], decreasing the V/III pressure ratio from 20 to 4 leads to the appearance of $\mathrm{Tl}$ droplets [Fig. 6(b)]. Finally, increasing the $\mathrm{Tl}$ flux
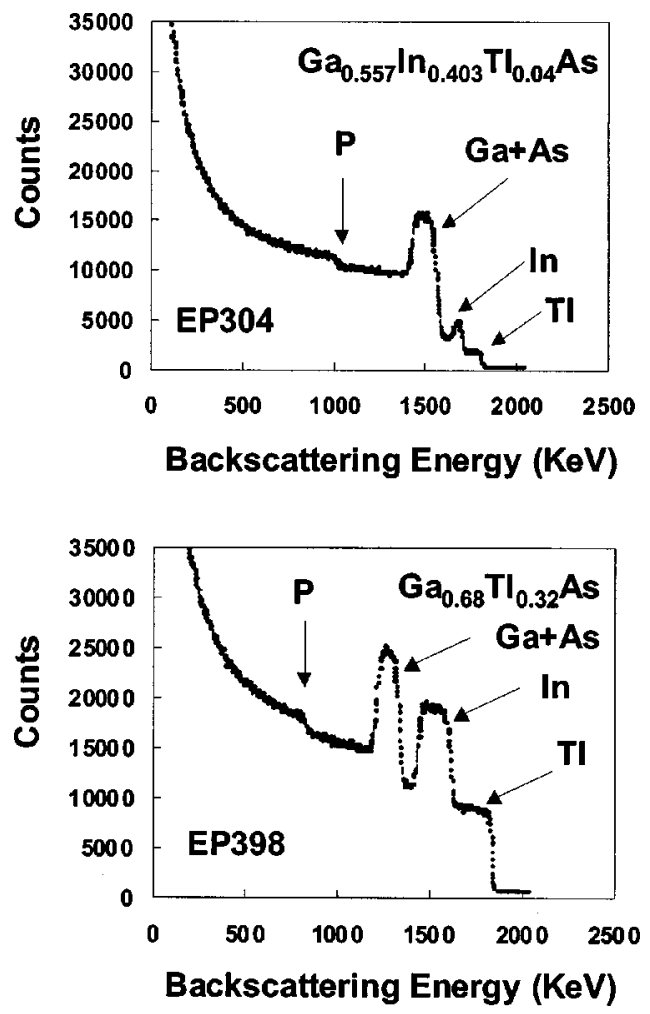

FIG. 3. RBS spectra of GaInTlAs showing incorporation of thallium into the bulk. Analysis conditions: ${ }^{4} \mathrm{He}^{+}$ions of $2 \mathrm{MeV}$ energy; detection angle $=150^{\circ}$. 


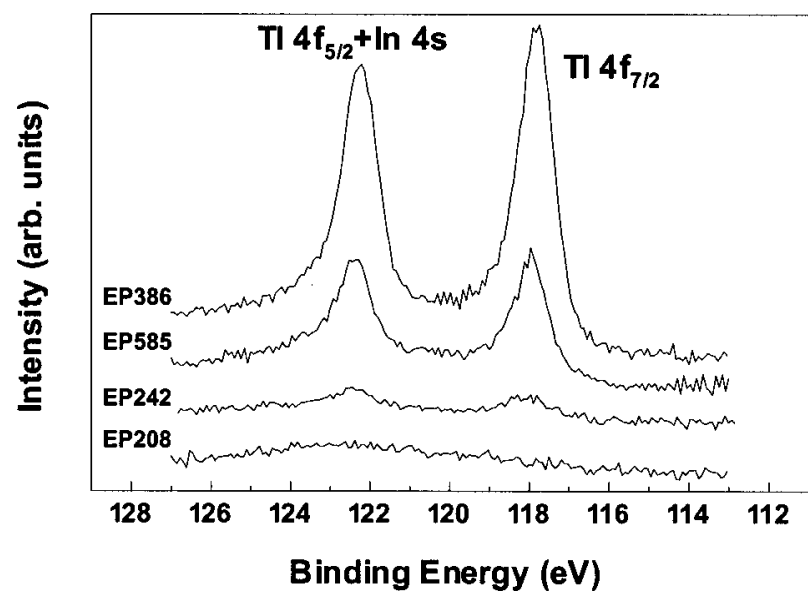

FIG. 4. XPS spectra taken at normal emission for the Tl $4 f$ region of three samples with increasing Tl content: EP242: 1\%, EP585: 4\%, EP386: 15\%. The samples have been deoxidized before introduction into vacuum in order to limit surface contribution effects.

when keeping all the other growth parameters constant can also lead to a transition from $\mathrm{Tl}$ incorporation to $\mathrm{Tl}$ surface coalescence (see Fig. 1). This has to be associated to an As overpressure not high enough.

RHEED pattern observations during growth show that, generally, the GaInTlAs alloys are defective and cannot be grown as a thick single crystal. At $180^{\circ} \mathrm{C}$, the layers are polycrystalline or amorphous. At $230^{\circ} \mathrm{C}$, the GaInTlAs layers grow first epitaxially $(1 \times 1$ RHEED pattern) but rapidly become twinned and then polycrystalline (see Fig. 7). This is illustrated by the cross section TEM image shown also in Fig. 10. About $80 \AA$ of single-crystalline GaInTlAs was grown before twins were formed. The twinning character lead to a final polycrystalline phase. The poor structural quality of the layers was confirmed by high resolution $\mathrm{x}$-ray diffraction measurements which did not show any peak associated to the GaInTlAs layers.

This behavior was mainly attributed to limitation of surface mobility of group III and V species due to the low growth temperature and to the high arsenic fluxes. It is well known that low temperature epitaxy and high arsenic fluxes limit surface mobility and allow arsenic incorporation ${ }^{15}$ leading to an arsenic excess incorporation within the layers. In fact, RBS (As/Ga ratio) and XPS (elemental As/As bonded to group III elements ratio) measurements have shown, for layers grown at $180^{\circ} \mathrm{C}$, a huge elemental arsenic incorporation up to several tens of percents. In contrast, at $230^{\circ} \mathrm{C}$ we did not detect any As incorporation within RBS and XPS sensitivity (a few percent). However it is expected, on the basis of the literature, that the amount of excess arsenic incorporated at $230^{\circ} \mathrm{C}$ could be less than $1 \%$ or $2 \% .^{16,17}$ As such highly defective materials are of no interest for applications, we tried to find conditions such that a single crystal growth process can be performed in the low temperature range .
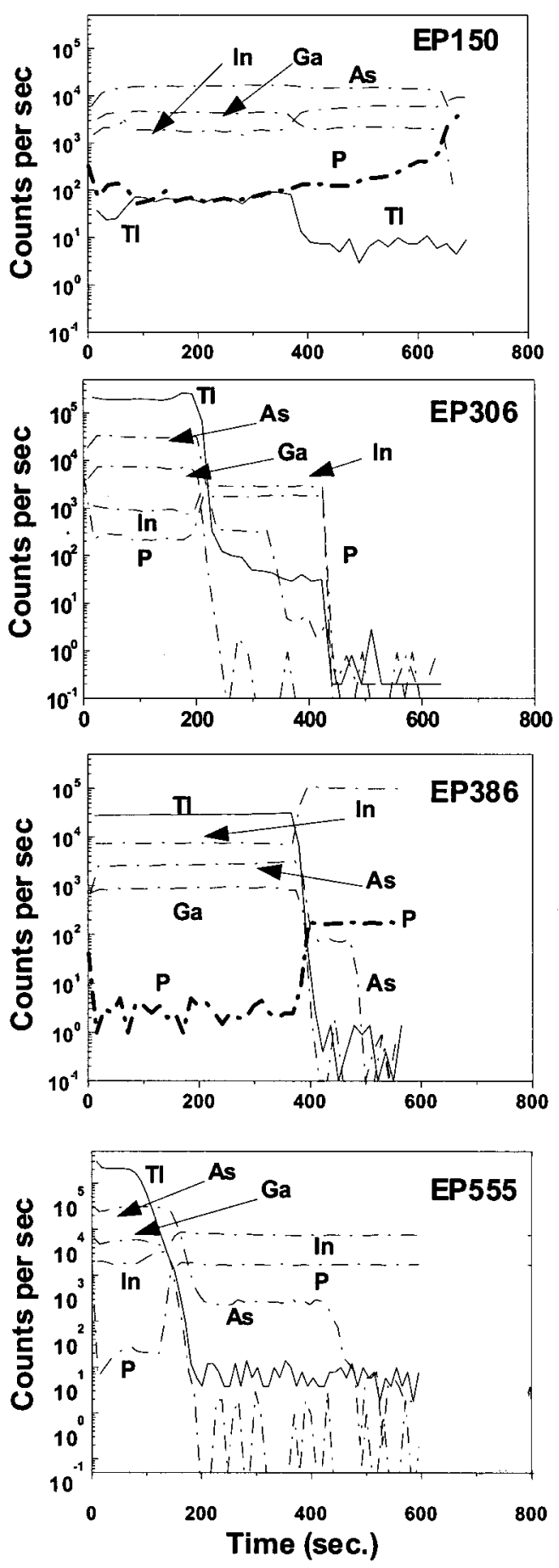

FIG. 5. SIMS profiles for four samples prepared in various conditions. Sample EP150 prepared at high temperature displays only $\mathrm{Tl}$ incorporation at the doping level. Samples EP306 (polycrystalline), EP386 (single crystalline/polycrystalline), and EP555 (single crystalline) prepared at low temperature show a thallium signal about 400 times higher than that of the high temperature sample.

\section{Growth of single-crystalline GalnTIAs at low temperature}

Low temperature MBE in semiconductors has been widely studied for both fundamental and application reasons. ${ }^{15}$ As an example, GaAs has been grown epitaxially at $75^{\circ} \mathrm{C}$ while maintaining a high crystalline perfection. ${ }^{18}$ 

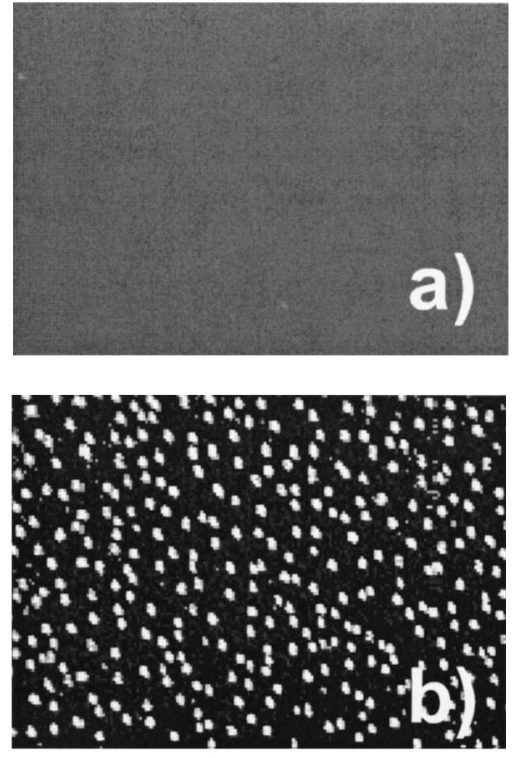

FIG. 6. Nomarski photographs of surface morphologies for two $\mathrm{Ga}_{0.58} \mathrm{In}_{0.42} \mathrm{As}$ : $\mathrm{Tl}$ samples grown at $200{ }^{\circ} \mathrm{C}$ with $\mathrm{V} / \mathrm{III}$ pressure ratios of 20 (a) and 4 (b), respectively. Keeping other growth conditions identical, incorporation of $\mathrm{Tl}$ is favored when using high arsenic fluxes rather than low arsenic fluxes. At these temperatures a mirror-like surface is indicative of $\mathrm{Tl}$ incorporation whereas droplets reveal $\mathrm{Tl}$ surface segregation and no incorporation.

This was achieved by controlling the incorporation of excess arsenic using low V/III ratio and using migration enhanced epitaxy techniques. Using more conventional MBE techniques, Kunzel et al. ${ }^{17}$ were able to grow single-crystalline $\mathrm{Ga}_{0.47} \mathrm{In}_{0.53}$ As layers on InP down to $125^{\circ} \mathrm{C}$.

As $\mathrm{Tl}$ incorporation necessitates the highest possible As overpressure, we first defined the substrate temperature-As

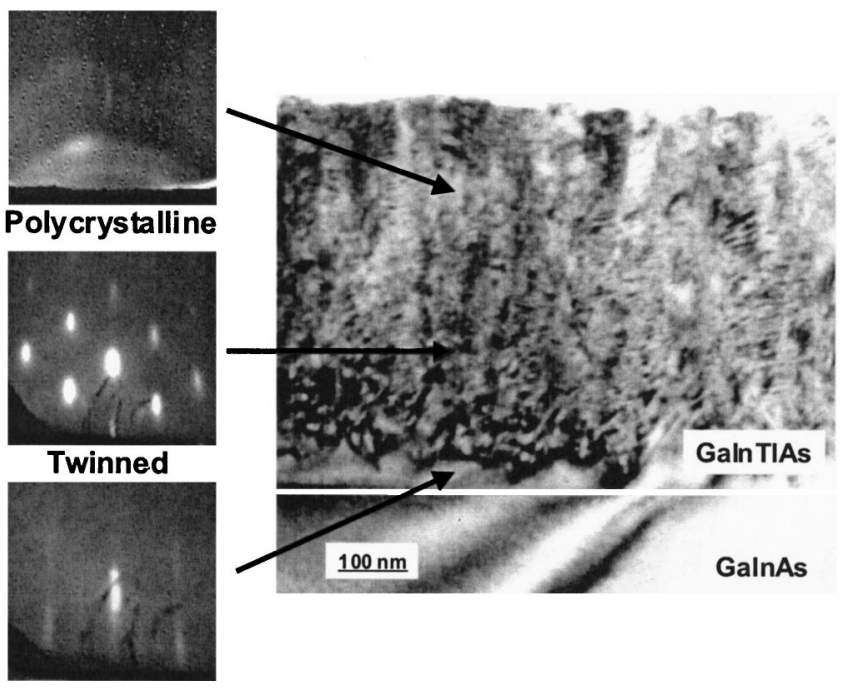

Single crystal

FIG. 7. Plan-view TEM image (right hand side) of $\mathrm{Ga}_{0.56} \mathrm{In}_{0.40} \mathrm{Tl}_{0.04} \mathrm{As}$ sample EP353 grown at $230^{\circ} \mathrm{C}$ showing, successively from the interface, single crystal, twinning, and polycrystalline growth. The corresponding RHEED patterns taken during growth are also presented (left hand side). overpressure domain where $\mathrm{Ga}_{0.47} \mathrm{In}_{0.53} \mathrm{As}$ layers can be grown epitaxially. The single crystallinity was checked by the presence of the reciprocal lattice rods in the RHEED patterns and by the existence of a peak in the DCXRD rocking curves. Figure 8(a) shows the growth conditions for lattice-matched GaInAs single-crystalline layers, twinned materials, and amorphous layers. It appears that singlecrystalline layers can be obtained in a wide range of V/III ratios in the $200-260{ }^{\circ} \mathrm{C}$ temperature range. Similar results have been obtained for two growth rates, 0.35 and $1 \mu \mathrm{m} / \mathrm{h}$. The single crystal domain for strained lattice-mismatched layers was not explored but it is expected that it could be slightly reduced.

On the basis of the results shown in Fig. 9(a), it is clear that we could expect to grow a single crystal material at $200{ }^{\circ} \mathrm{C}$ only for V/III ratios much lower $(<15)$ than those previously used to achieve high $\mathrm{Tl}$ content (i.e., V/III of 26 for $18 \% \mathrm{Tl}$ in $\left.\mathrm{Ga}_{0.70} \mathrm{In}_{0.30} \mathrm{As}\right)$. However these ratios should be compatible with the growth of GaInTlAs containing $\mathrm{Tl}$ less than $10 \%$. Consequently, we explored a wide range of V/III ratios-substrate temperatures conditions, for two growth rates, 0.35 and $1 \mu \mathrm{m} / \mathrm{h}$ and for nominal $\mathrm{Tl}$ concentrations from $1 \%$ to $12 \%$ in tensilely strained $\mathrm{Ga}_{0.58} \mathrm{In}_{0.42} \mathrm{As}$ matrices, staying in the vicinity of the "droplet formation"/ "Tl incorporation" boundary. The thickness of the GaInTlAs layers were $500 \AA$. In most cases the GaInTlAs layer was grown on a $200 \AA$ GaInAs lattice-matched layer. We checked that growing the GaInTlAs layer directly on the InP buffer layer gives similar results. Some characteristic growth conditions are given in Table III for a set of representative GaInTlAs and reference GaInAs layers.

First, we explored growth conditions at low growth rate $(0.35 \mu \mathrm{m} / \mathrm{h})$. The results are reported in Fig. 8(b). A comparison of Figs. 8(a) and 8(b) indicates that adding a Tl flux (4\% nominal composition) during growth of a GaInAs single-crystalline layer leads automatically to a twinned material for the highest V/III ratios or to $\mathrm{Tl}$ droplets for the lowest V/III ratios, with no window for single crystal growth.

Increasing the growth rate from 0.35 to $1 \mu \mathrm{m} / \mathrm{h}$ modifies completely the phase diagram [Fig. 8(c)]. As an example, for a $230{ }^{\circ} \mathrm{C}$ growth temperature, the droplet region appears at a much lower V/III ratio, 3, than it was $(\sim 10)$ for $0.35 \mu \mathrm{m} / \mathrm{h}$. Interestingly, a single crystalline window appears now between the "droplet" and the "twinning" regions. This window exists only for low $\mathrm{Tl}$ contents $(1 \%-4 \%)$. For $\mathrm{Tl}$ concentrations from $4 \%$ to $12 \%$, no single-crystalline growth conditions have been found yet. The single crystallinity of the $\mathrm{Ga}_{0.56} \mathrm{In}_{0.40} \mathrm{Tl}_{0.04} \mathrm{As}$ layers was shown by a $(1 \times 1)$ RHEED pattern during growth and by a peak in the (004) DCXRD rocking curves. It was confirmed by plan-view TEM [Fig. 9(a)]. The corresponding electron diffraction pattern [Fig. 9(b)] does not show any additional spot when compared with a single crystal $\mathrm{Ga}_{0.58} \mathrm{In}_{0.42} \mathrm{As}$ substrate taken as reference. However, these layers are characterized by a high density $\left(\sim 10^{9} \mathrm{~cm}^{-2}\right)$ of structural defects. The same density of defects is found by AFM on the surface of the layers 

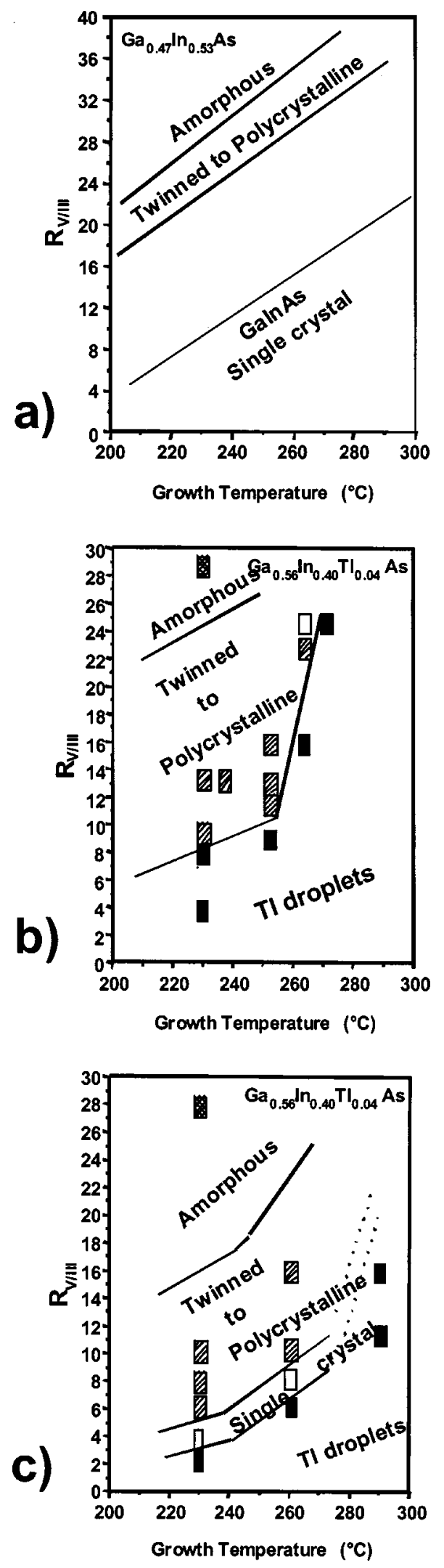

FIG. 8. Growth conditions at low temperature for single crystalline, twinned, polycrystalline, and amorphous layers. (a) $\mathrm{Ga}_{0.47} \mathrm{In}_{0.53} \mathrm{As}$, (b) $\mathrm{Ga}_{0.56} \mathrm{In}_{0.40} \mathrm{Tl}_{0.04} \mathrm{As}$ grown at $0.35 \mu \mathrm{m} / \mathrm{h}$, and (c) $\mathrm{Ga}_{0.56} \mathrm{In}_{0.40} \mathrm{Tl}_{0.04} \mathrm{As}$ grown at $1 \mu \mathrm{m} / \mathrm{h}$. where round and convex holes with a diameter of about 70 $\mathrm{nm}$ and a height of $2 \mathrm{~nm}$ are observed. The origin of these defects has been related to stacking faults and twins by cross section TEM. Figure 10 shows a cross sectional TEM image showing single crystal areas and isolated twins. An interesting point is that twinning appears only after 150-200 $\AA$ growth. Twinning is believed to arise from roughening of the growth front due to low surface mobility of adatoms and from the development of $\{111\}$ facets. It is also clearly associated to thallium atoms since, using identical growth conditions, thick single crystal GaInAs layers can be grown without any twinning. For the single-crystalline layers, x-ray chemical analysis associated to TEM measurements showed that thallium is incorporated homogeneously in the layers.

Using the same growth conditions, $4 \% \mathrm{Tl}$ was also successfully incorporated into $\mathrm{Ga}_{0.47} \mathrm{In}_{0.53} \mathrm{As}$ lattice-matched matrices and into $\mathrm{Ga}_{0.35} \mathrm{In}_{0.65}$ As compressively strained matrices, leading to single-crystalline layers. We explored more deeply growth conditions for lattice-matched host matrices (see Table III). Again, single crystal growth was achieved for $\mathrm{Tl}$ contents equal to or less than $4 \%$ and twinning occurred for $\mathrm{Tl}$ content of $8 \%$ and $12 \%$.

Figure 11 shows a set of DCXRD rocking curves taken for a nominal $\mathrm{Ga}_{0.53} \mathrm{In}_{0.43} \mathrm{Tl}_{0.04} \mathrm{As}$ layer and for a reference $\mathrm{Ga}_{0.55} \mathrm{In}_{0.45}$ As layer. The two layers have been grown one after another while keeping all growth conditions and flux parameters identical. It appears that both layers are single crystalline and that thallium incorporation is associated to an increase of the lattice parameter. This behavior is in agreement with the $6.18 \AA$ theoretical lattice parameter expected for $\mathrm{TlAs}^{1}$ but differs from a recent result where it was observed, in III antimonides, a lattice contraction of InTISb layers upon $\mathrm{Tl}$ incorporation. ${ }^{19}$ The observed shift would correspond to $2.2 \% \mathrm{Tl}$, assuming that the GaInTlAs layer is fully strained and to $6.9 \%$, assuming it is fully relaxed. These values are in reasonable agreement with the expected $4 \%$ actual $\mathrm{Tl}$ concentration. Note that in our calculations we supposed the same concentration of interstitial elemental arsenic in both GaInTlAs and GaInAs layers.

The corresponding TEM cross section image shows that the initial growth is defect free and $\{111\}$ twinning and stacking faults begin to appear after about $300 \AA$ growth. This is in agreement with RHEED observations during growth. One can conclude that $\mathrm{Tl}$ incorporation seems not to be influenced by the composition of the host matrix, at least for low $\mathrm{Tl}$ contents. Kinetic effects associated to the behavior of thallium atoms on the surface growth front appear to prevent growing high quality materials with high $\mathrm{Tl}$ contents.

\section{DISCUSSION}

At high temperatures, no thallium incorporation in arsenides was found whatever the conditions used (low/high sticking coefficients, low/high $\mathrm{Tl}$ pressures, tensilely or lattice-matched matrices, low/high arsenic overpressures...). This is in agreement with the thermodynamical predictions of Berding et al. ${ }^{20}$ At intermediate temperatures $\left(\sim 350{ }^{\circ} \mathrm{C}\right)$ where the sticking coefficient is equal to 1 , thallium atoms 
TABLE III. Growth conditions for a set of representative $\left(\mathrm{Ga}_{1-y} \mathrm{In}_{y}\right)_{1-x} \mathrm{Tl}_{x} \mathrm{As}$ layers and reference samples showing either single crystal growth, surface droplets, or twinning when varying some parameters.

\begin{tabular}{|c|c|c|c|c|c|c|c|c|}
\hline \multirow[b]{2}{*}{ Sample } & \multirow{2}{*}{$\begin{array}{l}\text { Growth } \\
\text { temperature } \\
\left({ }^{\circ} \mathrm{C}\right)\end{array}$} & \multirow{2}{*}{$\begin{array}{c}\text { As } \\
\text { pressure } \\
\text { (Torr) }\end{array}$} & \multirow{2}{*}{$\begin{array}{l}\mathrm{V} / \mathrm{III} \\
\mathrm{BEP} \\
\text { ratio }\end{array}$} & \multirow{2}{*}{$\begin{array}{l}\text { Growth } \\
\text { rate } \\
(\mu \mathrm{m} / \mathrm{h})\end{array}$} & \multicolumn{2}{|c|}{$\begin{array}{c}\text { Composition } \\
\left(\mathrm{Ga}_{1-y} \mathrm{In}_{y} \mathrm{As}\right)_{1-x}(\mathrm{TlAs})_{x}\end{array}$} & \multirow[b]{2}{*}{ Crystallinity } & \multirow{2}{*}{$\begin{array}{l}\text { Surface } \\
\text { morphology }\end{array}$} \\
\hline & & & & & $y \% \mathrm{In}$ & $x \% \mathrm{Tl}$ & & \\
\hline EP353 & 230 & $7.1 \times 10^{-6}$ & 14 & 1 & 42 & 4 & polycrystalline & mirror like \\
\hline EP555 & 230 & $2.3 \times 10^{-6}$ & 4 & 1 & 42 & 4 & single crystal & mirror like \\
\hline EP579 & 230 & $1.6 \times 10^{-6}$ & 3 & 1 & 42 & 4 & single crystal & droplets \\
\hline EP553 & 230 & $3.45 \times 10^{-6}$ & 6 & 1 & 42 & 4 & twinning & mirror like \\
\hline EP469 & 230 & $1.6 \times 10^{-6}$ & 8 & 0.35 & 42 & 4 & single crystal & droplets \\
\hline EP697 & 230 & $2.3 \times 10^{-6}$ & 4 & 1 & 55 & Ref. 0 & single crystal & mirror like \\
\hline EP698 & 230 & $2.4 \times 10^{-6}$ & 4.2 & 1 & 55 & 4 & single crystal & mirror like \\
\hline EP689 & 230 & $2.3 \times 10^{-6}$ & 4 & 1 & 55 & 4 & single crystal & droplets \\
\hline EP690 & 230 & $2.4 \times 10^{-6}$ & 4.2 & 1 & 55 & 8 & twinning & mirror like \\
\hline EP691 & 230 & $2.75 \times 10^{-6}$ & 4.8 & 1 & 55 & 12 & twinning & mirror like \\
\hline EP593 & 230 & $2.3 \times 10^{-6}$ & 4 & 1 & 65 & 4 & twinning & mirror like \\
\hline
\end{tabular}

segregate on the surface and behave like a surfactant giving a specific $2 \times 2$ surface reconstruction. This conclusion is in agreement with Antonell et al. ${ }^{8}$ and Wei et al. ${ }^{9}$ results but is in contradiction with Asahi and co-workers' claims. ${ }^{3-5}$ Note that Asahi et al. did not actually use a direct analytical technique to demonstrate the $\mathrm{Tl}$ incorporation in the layers.

We have shown that thallium can be incorporated at low temperature $\left(180-260^{\circ} \mathrm{C}\right)$ but with a high enough arsenic overpressure. In such conditions the Tl-As bond can be stabilized. However, the so-obtained layers are generally either amorphous, polycrystalline, or twinned. Nevertheless, for the lowest arsenic pressures, high growth rates and low $\mathrm{Tl}$ contents, a single crystal growth can be achieved even if after a few hundred angstrom growth, the surface roughening induces some structural defects. This behavior can be under-

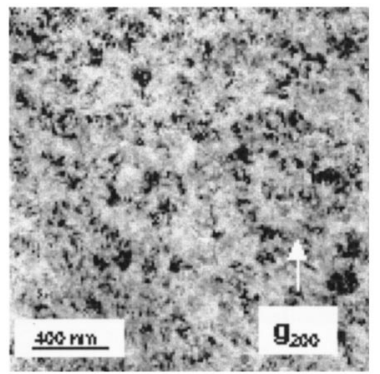

a)

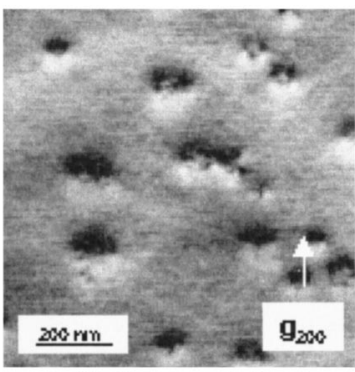

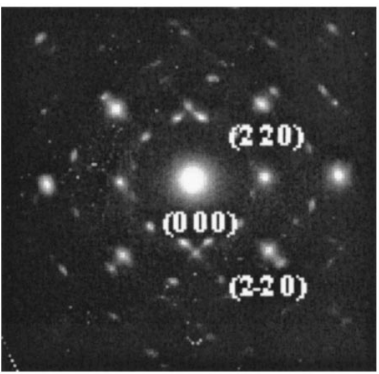

b)

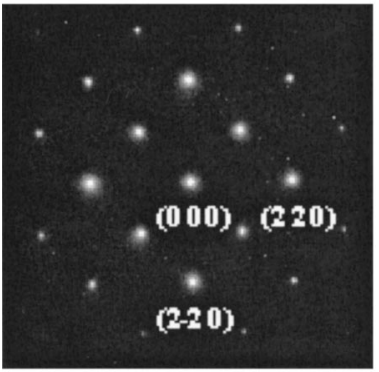

FIG. 9. Plan-view TEM images of (a) twinned and (b) single-crystalline $\mathrm{Ga}_{0.56} \mathrm{In}_{0.40} \mathrm{Tl}_{0.04} \mathrm{As}$ (EP555) layers grown at $230{ }^{\circ} \mathrm{C}$. The corresponding electron diffraction patterns are also shown. stood by considering a competition on the growth front between the formation of $\mathrm{Tl}-\mathrm{As}$ bonds and $\mathrm{Tl}-\mathrm{Tl}$ bonds.

As found experimentally, $\mathrm{Tl}$ atoms behave as surfactants and segregate on surface in standard growth conditions. $\mathrm{Tl}-\mathrm{As}$ bonds can be achieved at low growth temperature, only if enough $\mathrm{As}_{2}$ molecules are dissociated and if the vapor pressure above the weak $\mathrm{Tl}-\mathrm{As}$ bonds is high enough to prevent dissociation. ${ }^{20}$ As the dissociation rate of $\mathrm{As}_{2}$ molecules is low at such low temperatures, it is expected that Tl-As bonds can be stabilized only for relatively high arsenic overpressures. Unfortunately, high arsenic overpressures at low growth temperature prevents high quality growth and leads to the breakdown of crystallinity above a characteristic thickness, a behavior which is well known in low temperature epitaxy. ${ }^{15}$

Decreasing the As pressure, favors group III adatom mobility which could help to maintain epitaxial growth. However, it limits $\mathrm{Tl}-\mathrm{As}$ bond formation for the thermodynamical reasons given above and permits more time for the $\mathrm{Tl}$ atoms to move on the surface and reach other $\mathrm{Tl}$ atoms. Consequently $\mathrm{Tl}-\mathrm{Tl}$ bonds are favored and droplet formation could occur. To limit droplet formation, the average diffusion distance of $\mathrm{Tl}$ atoms has to be limited and this can be achieved by increasing the growth rate, as observed experimentally. Consequently, optimal growth can be achieved when different conditions are satisfied: (1) enough As pres-

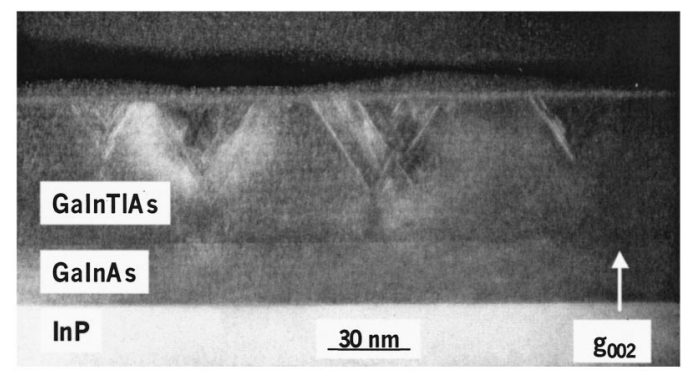

FIG. 10. [1 $\overline{1} 0]$ directional cross sectional TEM bright field micrograph of single-crystalline $\mathrm{Ga}_{0.56} \mathrm{In}_{0.40} \mathrm{Tl}_{0.04} \mathrm{As}$ (EP555) showing perfect single crystal areas with isolated twins. 


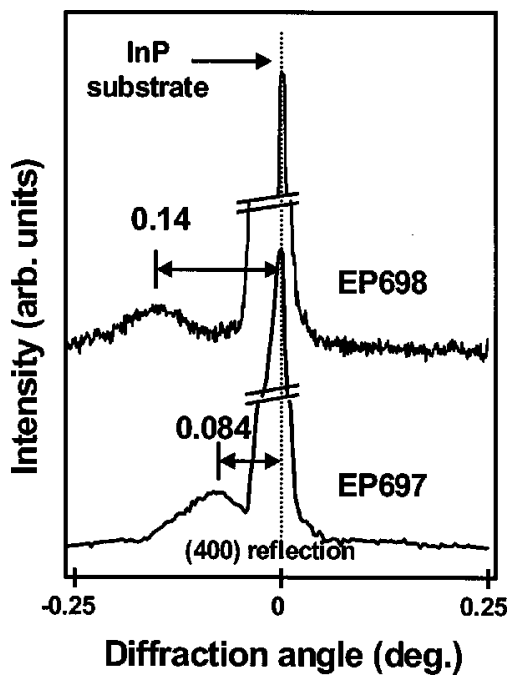

FIG. 11. (004) DCXRD curves for a single-crystalline $\mathrm{Ga}_{0.43} \mathrm{In}_{0.53} \mathrm{Tl}_{0.04} \mathrm{As}$ layer grown at $230^{\circ}(\mathrm{V} / \mathrm{III} \mathrm{BEP}$ ratio $=4)$ and of a reference sample, showing lattice expansion upon $\mathrm{Tl}$ incorporation.

sure to help formation of sufficient Tl-As bonds, (2) enough growth rate to limit $\mathrm{Tl}-\mathrm{Tl}$ bond formation, and (3) enough adatom mobility (temperature, V/III ratio) to allow single crystal growth. We found a set of critical parameters for $\mathrm{Ga}_{0.53} \mathrm{In}_{0.43} \mathrm{Tl}_{0.04} \mathrm{As}$ layers grown at $230^{\circ} \mathrm{C}$ which lead to epitaxial growth but without reaching perfect structural properties. For most other conditions (higher $\mathrm{Tl}$ content, higher As pressure, ...), the growth starts epitaxially and then turns to twinning, a behavior already observed in low temperature epitaxy. Breakdown of crystallinity for GaAs or GaInAs was previously considered to be due to surface roughness built during the early stages of growth. ${ }^{15}$ Roughening was associated to low adatom mobility and to some arsenic incorporation which adds additional compressive strain in the epilayer. As for similar conditions used at $230{ }^{\circ} \mathrm{C}$, perfect crystal growth is obtained for GaInAs and twinning for GaInTlAs, it appears that thallium atoms favor surface roughening at low growth temperature and help to break down epitaxy. The origin of $\mathrm{Tl}$ induced roughening and twinning is not clear yet. It may be related to any of three possible mechanisms: (1) the surfactant behavior of thallium atoms which would decrease the surface mobility of other adatoms, (2) the formation of small $\mathrm{Tl}$ clusters, and (3) the alloy demixing into $\mathrm{Tl}$ rich and $\mathrm{Ga}$ rich areas on the growth front.

In all three cases, the roughening effect is expected to be stronger as the $\mathrm{Tl}$ content is increasing.

Finally, we think that the way to decrease surface roughening and achieve single-crystalline layers containing a greater Tl percentage and of better structural quality, would be either to enhance the surface mobility of adatoms (while maintaining enough arsenic overpressure) using for example, mobility enhanced epitaxy or to enhance arsenic reactivity using plasma enhanced epitaxy. Work is in progress in these directions.

\section{CONCLUSION}

To summarize, we have shown that thallium can be incorporated in GaInAs matrices for low substrate temperatures $\left(180-260^{\circ} \mathrm{C}\right)$ and sufficiently high enough V/III ratios. The higher the expected $\mathrm{Tl}$ concentration is, the higher the V/III ratio should be. For high Tl contents, the high arsenic overpressure prevents to achieve single crystal growth and the layers are either amorphous, polycrystalline, or twinned. However a narrow window for single crystal growth has been found for low $\mathrm{Tl}$ contents (4\%) using optimized growth conditions with low V/III pressure ratios and high growth rates.

\section{ACKNOWLEDGMENT}

This work was partially supported by Région Rhône Alpes under Contract No. 97022185 and No. 97022194 . One author (G.H.) gratefully acknowledges H. Asahi, A. MunozYague, and N. Granjean for fruitful discussions. He also thanks H. Asahi and D. Lubyshev for sending him preprints before publication. The authors wish to thank C. Dubois, MP Besland, J. B. Goure, and F. Pinto for technical assistance. One author (F. S.) gratefully thanks the National Council of Science and Technology of Mexico (CONACyT) for the financial support given during his Ph.D. studies.

${ }^{1}$ M. van Schlifgaarde and A. Sher, Appl. Phys. Lett. 65, 2714 (1994).

${ }^{2}$ H. Asahi, K. Yamamoto, K. Iwata, S. Gonda, and K. Oe, Jpn. J. Appl. Phys., Part 2 35, L876 (1996).

${ }^{3}$ H. Koh, H. Asahi, M. Fushida, K. Yamamoto, K. Takenaka, K. Asami, S. Gonda, and K. Oe, J. Cryst. Growth 188, 107 (1998).

${ }^{4}$ H. Asahi, H. Koh, K. Takenaka, K. Asami, K. Oe, and S. Gonda, J. Cryst. Growth 201-202, 1069 (1999).

${ }^{5}$ A. Ayabe, H. Asahi, H. J. Lee, O. Maeda, K. Konishi, K. Asami, and S. Gonda, Appl. Phys. Lett. 77, 2148 (2000).

${ }^{6}$ A. Hubener, J. Schobel, A. Mallwitz, and W. Kowalsky, Eleventh International Conference on Indium Phosphide and Related Materials (IPRM '99), 16-20 May 1999, Davos, Switzerland.

${ }^{7}$ M. Razeghi, J. D. Kim, S. J. Park, Y. H. Choi, D. Wu, E. Michel, J. Xu, and E. Bigan, 22nd International Symposium Compound Semiconductors, Cheju Island, Korea, 28 August-2 September 1995 [Inst. Phys. Conf. Ser. 145, 1085 (1995)].

${ }^{8}$ M. J. Antonell, C. R. Abernathy, A. Sher, M. Berding, M. Van Schilfgaarde, A. Sanjuro, and K. Wong, J. Cryst. Growth 188, 113 (1998).

${ }^{9}$ J. Wei, M. R. Gokhale, and S. R. Forrest, J. Cryst. Growth 203, 302 (1999).

${ }^{10}$ D. I. Lubyshev, W. Z. Cai, G. L. Catchen, T. S. Mayer, and D. L. Miller, in Proceedings of the IEEE 24th International Symposium On Compound Semicoductors, edited by M. Melloch and M. A. Reed (Institute of Physics, Bristol, 1997), pp. 125-130.

${ }^{11}$ M. Lange, D. Storm, and T. Cole, J. Electron. Mater. 27, 536 (1998).

${ }^{12}$ F. Sánchez-Almazán, M. Gendry, P. Regreny, E. Bergignat, G. Grenet, J. Olivares, G. Bremond, O. Marty, M. Pitaval, and G. Hollinger, 2000 International Confrence on Indium Phosphide and Related Materials (IPRM '00), 14-18 May 2000, Williamsburg, Virginia.

${ }^{13}$ F. Sánchez-Almazán, M. Gendry, P. Regreny, E. Bergignat, G. Grenet, J. Olivares, G. Bremond, O. Marty, M. Pitaval, and G. Hollinger, Opt. Mater. (to be published).

${ }^{14} \mathrm{We}$ have also reproduced the photoluminescence (PL) data of Ref. 6 by growing "GaP:Tl" layers on GaAs. Like Hubener et al. we found a strong emission at $1.3 \mu \mathrm{m}$. In fact no $\mathrm{Tl}$ incorporation was found by SIMS and it appeared that the PL signal was related to GaP deep defects. 
${ }^{15}$ D. J. Eaglesham, J. Appl. Phys. 77, 3597 (1995).

${ }^{16}$ R. Metzger, A. Brown, L. McCray, and J. Henige, J. Vac. Sci. Technol. B 11, 798 (1993).

${ }^{17}$ H. Kunzel, J. Bottcher, R. Gibis, and G. Urmann, Appl. Phys. Lett. 61, 1347 (1992).
${ }^{18}$ P. Taylor, W. Jesser, M. Martinka, and J. Dinan, J. Appl. Phys. 85, 3850 (1999).

${ }^{19}$ J. J. Lee and M. Razeghi, Appl. Phys. Lett. 76, 297 (2000).

${ }^{20}$ M. A. Berding, M. Van Schilfgaarde, A. Sher, M. J. Antonell, and C. R. Abernathy, J. Electron. Mater. 26, 683 (1997). 